\title{
The Research and reform for Teaching of Electronic Technology Course Based on the Applied Innovative Talent
}

\author{
Rongrong Wang ${ }^{1, a}$, Fei $X u^{1, b}$, Tuanbu Wang ${ }^{1, c}$ and Liping Wang ${ }^{1, d}$ \\ ${ }^{1}$ Xijing university, Shaanxi Xi'an 7100123, China

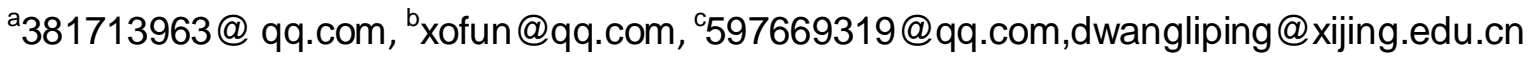

\begin{abstract}
Electronic technology is the important foundation of electronics and related professional courses. On the basis of analyzing the characteristics of the applied innovative talents, according to the situation of electronic technology course teaching, puts forward the method of electronic technology course teaching reform. System design the teaching content system, appropriate to the building and application of innovative ability training practice teaching platform, improving teaching methods and examination methods. To explore the new mode of applied innovative talents training.
\end{abstract}

Keywords: Applied innovative talengts; Electronic technology; Teaching reform

\section{基于应用型创新人才培养的电子技术课程教学改}

\section{革与研究}

\author{
王荣荣 ${ }^{1}$ ，王团部 ${ }^{1}$ ，徐飞 ${ }^{1}$ ，王利平 ${ }^{1}$
}

(1.西京学院, 陕西西安 710123 )

摘要: 电子技术是电子及相关专业的重要基础课程。在分析应用型创新人才特点的基础上, 根据电子技术课程教学现状, 提出了电子技术课程教学改革的方法。系统设计了教学内容体系, 搭建与应用创新能力培养相适应的实践教学平台, 改进了 教学方法和考核方法。以探索应用型创新人才培养的新模式。

关键词: 应用型创新人才; 电子技术; 教学改革

中图分类号: G 642 文献标识码: A

引言

(1) 我国《国家创新驱动发展战略纲要》提出到 2020 年进入创新型国家行列。建设创新型国家, 在 很大程度上取决于创新人才的规模与质量, 而应用型创新人才培养又取决于高校的创新教育。应用型创新 人才的培养对实现社会经济、科技、文化等方面和谐、持续良好发展具有重要的意义。当前, 大学生应用 创新教育在全国各高校正蓬勃展开 ${ }^{[1-2]}$, 这是社会需求对高等教育提出的新课题。

电子技术类课程是电类相关专业在大学中必修的重要专业基础技术课程, 在应用型创新人才培养的大 环境下, 其教学模式需要进一步的改革和完善。电子技术类课程包含电路分析、模拟电子技术、数字电子 技术、传感器技术、单片机等, 这些课程在构建学生电子技术基本理论、基本技能和创新能力方面具有不 可替代的重要作用。近年来, 针对在应用型创新人才培养模式中电子类课程的教改研究国内许多高校的教 育专家和从业者开展了积极的探索和实践 ${ }^{[3-5]}$ 。

本文在分析电子技术课程教学现状的基础上, 强调在培养体系和教学内容、方法、手段等方面进行改 革, 探索电子技术课程教学模式的改革。重点就电子技术课程的教学内容进行了整合, 搭建有效的实验平 台, 更大地激发学生的学习兴趣和求知欲望, 充分调动学生的学习积极性和主动性, 分层次、分阶段培养 学生的应用创新能力。 


\section{1 应用型创新人才的特征}

应用型创新人才是能够将科学技术创造性地应用于生产实践的人才。具有精湛的技艺能力，掌握一定 复合型和综合性特征的技术, 包括理论技术、实践经验, 能将专业知识和技能应用于所从事专业。其具备 如下基本特征 ${ }^{[6]}$ :

（2）具有解决实际问题的知识应用能力。掌握丰富的知识, 能够综合运用多学科、跨学科的知识, 集 成知识, 并应用于实际问题, 具有创造性地解决问题的能力。

(3) 具有敏锐的观察能力, 善于发现问题。能从生产实际中发现问题, 必须具备敏锐的观察能力。

(4) 探索学习和研究能力。具备较强的科学探索意识和探索精神, 在注重学习能力培养和发展的同 时, 还应当具有一定的开拓意识和研究开发能力。

（4）良好的沟通交流和相互协作能力。沟通是知识交流与共享的基础，也是知识转化的重要条件。 这不仅是指对文化、社会、语言、科技等的了解, 还应包含与人交往的能力与融洽的能力。团队共同协作 能力是应用型创新人才的基本素养。

\section{2 电子技术课程的教学现状}

\section{1 教学方法不利于创新能力的培养}

目前, 在多数本科院校中, 电子技术课程的教学都采用传统的教学模式, 以教师所选教材的章节内容 及所授专业的教学大纲按部就班地进行授课, 然后再配合一些实验项目对理论知识进行验证。课堂以教师 讲授为主要教学形式, 学生是被动的学习。这种教学模式往往会导致教学过程枯燥, 学生失去学习兴趣, 主动性不强。

各门课知识自成体系, 仅完成本课程的教学内容, 缺乏课程之间的相互交叉应用方面的内容。在课程 结束后, 由于缺乏知识系统应用方面的训练, 学生对不同课程知识体系不能融汇贯通。在实际工程中的应 用一知半解, 对于解决实际问题更是感到无从入手。忽略学生综合分析问题和解决问题的能力的培养, 也 不利于创新型人才的培养。

\section{2 教学内容落后于人才市场要求}

目前人才市场对电子类专业的要求在不断提高, 而大部分高等院校本科层次电子类专业仍然只开设一 些传统的专业基础或专业课程。教学内容更新量比较少, 更新速度慢, 以及本专业所涉及到的新领域、新 内容、新技术非常欠缺, 滞后于实际应用。此外, 理论教学课时量远大于实践教学课时量, 属于传统的重 理论轻实践思想。以模拟电子技术课程和数字电子技术课程为例, 在教学内容上, 无论是理论还是实践环 节都偏重于原理性的讲授或验证，而对于其他方面的知识，如现实中电子技术应用到什么程度、出现哪些 新的元器件、典型的应用电路、专业软件、生产制作过程及相应的仪器设备、社会的需求等基本上没涉及 到，或涉及很少。结果出现了企业招不到合适的人才，而很多毕业学生找不到合适工作的现象。

\section{3 创建新的教学内容体系}

电子技术课程具有电路种类多、器件工作状态复杂、电路分析方法灵活等特点，以体现应用能力的培 养为主线, 对教学内容进行整合。

（1）将《电路分析》课程与《模拟电子技术》课程相结合。在保证基本概念、基本原理和基本分析 
方法的前提, 压缩分立元件电路内容, 而加强电路的分析和应用。强调用电路分析课程中的分析方法解决 模拟电路中的问题，培养学生电路的识别与分析能力。

(2) 将《传感器技术及应用》与《模拟电子技术》课程相结合。对传感器采集的信号, 用模拟电路 中的基本放大器、差动放大器、功率放大器、运算放大器、反馈放大器内容进行分析处理研究, 培养学生 实际电路的设计能力。

(3) 采用项目化教学。使项目任务内容涵盖《传感器技术及应用》、《模拟电子技术》、《数字电 子技术》、《单片机》课程。使学生掌握从信号采集、处理、转换到控制电路的设计、制作、调试, 进行 系统技能的训练, 培养学生实际的工程技术能力。

（4）体现 “新” 字。在教学内容中引入新器件、新技术、新工艺和新方法。尽量采用实际的器件或 芯片, 举应用实例, 使学生及时了解电子技术市场变化。

最终, 使课程内容的安排以培养学生掌握看电路图能力、电路分析计算能力、选择设计方案和器件应 用能力、电路设计及调试能力为目标, 培养学生应用创新能力。

\section{4 搭建与应用创新能力培养相适应的实践教学平台}

在传统的教学模式中, 实验教学内容大多是验证性实验, 内容陈旧, 不利于学生创新思维及创新能力 的培养。针对此情况，对实验教学内容及考核方式进行改革 ${ }^{[7]}$, 将实验室分三个层次。

(1) 基础实验室。服务对象主要为初学者, 主要提供基础性实验内容, 有确定的实验项目, 给出详 细的实验内容、所用仪器设备、操作方法、操作步骤, 其目的是使学生掌握基本电子仪器的使用、电子技 术实验的基本技能和基本方法, 了解电子仪器、器件的基本功能和应用。这些是学习后续课程的基础, 也 是将来从事专业工作所需的基本技能。

(2) 开放相实验室。主要为项目化实践教学服务, 同时为有兴趣的学生提供课外服务。教师给出项 目名称和基本要求, 由学生根据所学理论知识设计方案、选择元器件、实验仪器设备, 经指导教师审查后 实施后实施。主要目的提高学生理论联系实际的能力和设计能力, 同时它也能锻炼学生独立工作能力。

(3) 竞赛培训实验室。为各类竞赛提供系统培训, 为培养学生知识综合能力、创新能力提供平台。 例如, 在电子设计竞赛培训中, 学生根据教师培训的内容, 完成设计任务。教师提出设计要求, 由学生以 团队形式完成任务, 通过文献的查阅、方案的论证比较、自己设计电路、进行电路仿真、制作、调试, 完 成作品设计报告。由于此类实践活动涉及电子、机械、计算机等多学科知识, 是学生对知识的升华过程, 因此, 培养了独立分析问题、解决问题的能力。对提高学生综合运用知识分析问题的能力、创新能力起到 至关重要的作用, 同时, 也提高了学生团队协作意识。

\section{5 改进教学方法和考核方法}

\section{1 教学方法的改进}

电子技术这门课程传统的教学方式，一般是教师在多媒体教室中以课堂讲授的方式完成的，同时辅以 一定学时的实验教学。在此基础上, 对教学方法进行改进 ${ }^{[8-10]}$ :

(1) 实行项目化教学。根据不同的教学内容选择不同的项目任务, 以项目任务驱动教学, 使学生将 理论知识应用到具体的实践操作中, 从而激发学生对电子技术这门课程的学习兴趣。项目任务, 可以是电 路搭接实验、电路仿真、电路实物制作等形式。实验可以是综合性、扩展性的实验, 但是这并不意味着要 
去增加实验的难度, 而是增加实验的趣味性和实用性, 这样可以培养学生的实践兴趣和创新能力。电路仿 真要教会学生使用常见的电子仿真软件, 例如 Multisim 仿真软件、Proteus 仿真软件等。电路实物制作 可以是一些功能电路，小作品等。

（2）引入微课、翻转教学法。录制微课视频, 使学生不受时间、地点限制, 随时方便观先看微课视 频, 学习知识。实施翻转课堂教学, 使学生学习更加灵活、主动, 让学生的参与度更强。实施好翻转课堂 教学法不但激发出学生极大的关注和积极性, 还可以极大的激发学生的学习兴趣。

\section{2 考核方式的改革}

打破传统的试卷考试模式, 采用过程考核, 把对学生的考核贯穿到整个教学的过程中, 按照任务难易 程度赋予不同的比重, 用每项任务的考核成绩综合作为最终的成绩。这种考核方式贯穿整个学习过程的考 核方式能全面地对学生的自主学习能力、分析解决问题能力、创新能力、沟通协调能力等多方面的综合素 质进行考核。同时, 以每个阶段性的考核来不断促进学生努力提高自己的综合能力, 缩短学校课堂教学与 市场实际需求之间的距离，达到了应用型创新人才的要求和目的。

\section{6 结束语}

以应用型创新人才培养为导向的电子技术课程的改革是各高校正在尝试的一个方向。结合应用型创新 人才培养的特点, 在知识模块化的基础上实现内容的层次化, 着重突出实践应用技能培养, 能够充分地提 高学生的应用实践能力和综合创新能力。电子技术课程的教学改革与研究对提高教学质量, 对学生创新、 应用能力的培养具有积极的意义。

\section{参考文献:}

[1] 张洪. 基于应用型创新人才培养的实践教学改革探究 [J].现代教育技术，2015.25(10):119-125. 吴

[2]朱梦冰, 刘晶如, 杨燕. 应用型创新人才培养实践教学改革 [J]. 实验室研究与探索, 2016.35 (7) : 186-189.

[3] 贾立新, 龙忠琪, 李如春. 电子技术课程建设探索与实践 [J]. 电气电子教学学报, 2004. 26 (2) : 31-33.

[4] 秦宏, 曲延华, 黄硕. 应用型本科电子技术课程工程实际能力的培养与实践 $[J]$. 沈阳工程学院学报 (社会科学 版), 2009. 5(4):555-557.

[5] 关静. 应用型本科院校电子技术类课程设计的研究与改革 [J].中国现代教育装备, 2010. 21：102-104.

[6] 吴中江, 黄成亮. 应用型人才内涵及应用型本科人才培养 $[J]$. 高等工程教育研究，2014. 2:66-70.

[7] 叶朝辉, 华成英, 问捷. 模拟电子技术实践创新能力培养的探索. 实验技术与管理, 2017. 34 (1)：29-32.

[8] 姜明, 金佳南, 温照芳. 关于电子技术课程教学改革的几点思考 [J]. 教育教学论坛, 2016, 47:99-100.

[9] 杨玉强, 腾香, 戴心来. 电子技术课程的改革研究与实践 [J]. 电气电子教学学报, 2006. 28 (2):12-14.

[10］孙静晶, 张鹏. 电子技术课程设计的教学改革与实践 [J]。漯河职业技术学院学报, 2016. 15(5): 76-78.

\section{References}

[1] Zhang Hong: "Probe into Practical Teaching Reform of Cultivating Talents with Application and Innovation Ability" [J]. Modern educational technology, Vol. 25(2015), No.10, p. 119-125 (in Chinese)

[2] Zhu Meng-bing, Liu Jing-ru, Yang Yan: "Practical Teaching Reform Based on Training Applied Innovative Talents" [J]. Research and Exploration in Laboratory, Vol. 35(2016),No.7), p.186-189(in Chinese)

[3] Jia Li-xin, Long Zhong-qi, Li Ru-chun: "The Exploration and Practice of E lectronic Technique Course Construction” [J]. Journal of EEE, Vol. 26(2004), No.2, p.31-33(in Chinese) 
[4] Qin Hong, Qu Yan-hua, Huang Shuo: "Practice of cultivating actual engineering ability in electronic technology course of applied four-year programme" [J]. Journal of Shenyang Institute of Engineering(Social Sciences), Vol. 5(2009), No.4, p.555-557(in Chinese)

[5] Guan Jing: "The research and reform of the electronic technology class course design in the application-oriented institutes"[J].China Modern Educational Equipment, Vol.21(2010)p.102-104 (in Chinese)

[6] Wu Zhong-jiang, Huang Cheng-liang: "The Concept and Cultivation of Applied Talents "[J]. Research in Higher Education of Engineering, Vol. 2 (2014), p. 66-70 (in Chinese)

[7] Ye Chao-hui, Hua Cheng-ying, Yan jie: "Exploration on cultivation of practical and innovative ability of analog electronic technology" [J]. Experimental Technology and Management, Vol. 34(2017), No.1, p. 29-32 (in Chinese)

[8] Jiang Ming, Jin Jia-nan, Wen Zhao-fang: “On New Ways of Teaching Concerning Electronic Technology Course” [J]. Education eaching Forum, Vol. 47(2016), p.99-100(in Chinese)

[9] Yang Yu-qiang, Teng Xiang: "Dai Xinlai. Study ang Practice on Course Reform of Electronic Technology in University" [J]. Journal of EEE, Vol. 34(2006), No.2, p.12-14 (in Chinese)

[10] Sun Jing-jing: "Zhang Peng. Teaching Reform and Practice in Electronic Technology Course Design" [J]. Journal of Luohe Vocational Technology College, Vol.15(2016), N0.5, p.76-78(in Chinese) 